\title{
Pemberdayaan Duta Keluarga Tuberkulosis sebagai Upaya Mencegah terjadinya TB Multi Drugs Resistent di Puskesmas Sidomulyo RJ Pekanbaru
}

\author{
Tri siwi Kusumaningrum*, Maswarni, Yuyun Ria Wahyuni \\ Fakultas MIPA dan Kesehatan \\ Universitas Muhammadiyah Riau \\ email: trisiwi@umri.ac.id
}

\begin{abstract}
Tuberculosis is an infectious disease that can attack the lungs and extra-pulmonary organs. Patients with TB must undergo treatment for 6-8 months. If you do not take medication completely, it can cause germ resistance called TB Multi Drugs Resistent which can endanger the health of yourself or others. Patients who experience MDR TB will undergo trials with a longer period of time with a combination of drug injections orally. This will increase the body workload of TB sufferers so that they can experience a variety of more severe complaints while undergoing treatment. The purpose of this Community Service activity is to provide insight to families on how to establish effective communication to motivate $T B$ sufferers to take medication to recover and also provide motivation and education to TB sufferers about the side effects of anti-TB drugs and their management. The PKM method uses lectures and discussions to find solutions to problems experienced by patients and families in the TB treatment process. In addition, by giving the card to take medicine to the Medication Companion as a medium to control the regularity of taking medicine. The results of PKM activities show the knowledge of PKM participants about TB disease and effective communication techniques to support TB sufferers taking medicine to recover the majority in the good category. apart from that $100 \%$ of TB sufferers take medicine regularly. There was a very good contribution and response from the Head of Puskesmas Sidomulyo RJ in the effort to prevent MDR TB.
\end{abstract}

Keywords: empowerment, family ambassadors, tuberculosis, community.

\begin{abstract}
Abstrak
Penyakit Tuberkulosis merupakan penyakit menular yang dapat menyerang organ paru maupun ekstra paru. Penderita TB harus menjalani pengobatan selama 6-8 bulan. Apabila tidak minum obat hingga tuntas dapat menyebabkan resistensi kuman yang disebut TB Multi Drugs Resistent (MDR) yang dapat membahayakan kesehatan diri sendiri maupun orang lain. Penderita yang mengalami TB MDR akan menjalani pengobaan dengan jangka waktu lebih lama dengan kombinasi pemberian obat secara injesi maupun oral. Hal ini akan menambah beban kerja tubuh penderita TB sehingga dapat mengalami berbagai keluhan yang lebih berat saat menjalani pengobatan. Tujuan kegiatan Pengabdian Kepada Masyarakat ini adalah untuk memberikan wawasan kepada keluarga bagaimana tips menjalin komunikasi efektif untuk memberikan motivasi penderita TB minum obat hingga sembuh dan juga memberikan motivasi dan edukasi kepada penderita TB tentang efek samping obat anti TB dan penatalaksanaannya. Metode PKM dengan menggunakan ceramah dan diskusi unuk mencari solusi permasalahan yang dialami oleh penderita dan keluarga dalam proses pengobatan TB. Selain itu juga dengan memberikan kartu minum obat kepada Pendamping Menelan Obat sebagai media untuk mengontrol keteraturan minum obat. Hasil kegiatan PKM menunjukkan pengetahuan peserta PKM tentang penyakit TB dan tehnik berkomunikasi efektif untuk mensupport penderita TB minum obat hingga sembuh mayoritas dalam kategori baik. selain itu $100 \%$ penderita TB minum obat secara teratur. Terdapat kontribusi dan respon yang sangat baik dari Pimpinan Puskesmas Sidomulyo RJ dalam upaya mencegah TB MDR.
\end{abstract}

Kata Kunci: pemberdayaan, duta keluarga, Tuberkulosis, komunitas 


\section{PENDAHULUAN}

Puskesmas Sidomulyo RJ merupakan salah satu fasilitas pelayanan kesehatan masyarakat yang ada di wilayah kerja Kecamatan Tampan Kota Pekanbaru, dengan jarak tempuh berkisar 5,6 km dari kampus Universitas Muhammadiyah Riau. Wilayah kerja puskesmas Sidomulyo RJ terdiri dari 3 kelurahan yaitu Kelurahan Delima, Tobek Godang dan Kelurahan Tangkerang Barat.

Terkait dengan Strategi Nasional (STRANAS) yang menetapkan tiga target untuk dicapai pada akhir tahun 2019, yaitu $30 \%$ penurunan angka kematian yang disebabkan oleh TB dibandingkan angka pada tahun $2014 ; 15 \%$ penurunan insidens dibandingkan pada tahun 2014 dengan mempercepat penurunan perkiraan insiden dari $1 \%$ pertahun menjadi $4 \%$ pertahun mulai tahun 2017 dan seterusnya ${ }^{1}$. Meskipun angka kesembuhan TB secara nasional menduduki angka $84 \%$, untuk mencapai target tersebut masih sulit untuk dicapai. Kasus TB MDR juga mengalami peningkatan dari tahun ke tahun. Data informasi TB tahun 2009-2015 menunjukkan adanya peningkatan kasus TB MDR dari 9.309 pada tahun 2014 dan meningkat menjadi 15.380 pada tahun $2015^{2}$.

Data dari Dinas Kesehatan Propinsi Riau, Puskesmas Sidomulyo RJ merupakan puskesmas yang memiliki data kasus TB urutan kedua dari 12 Puskesmas yang ada di Kota Pekanbaru dengan jumlah CNR 156,03/100 ribu penduduk. Sedangkan penderita TB yang putus obat TB sebanyak $21 \%{ }^{3}$. Penderita TB sering tidak menjalani pengobatan hingga tuntas karena mengalami berbagai keluhan mual, muntah, pusing serta telinga berdenging akibat efek samping obat TB yang dikonsumsi ${ }^{4}$.

Permasalahan yang dialami oleh penderita TB yang berobat di Puskesmas Sidomulyo RJ adalah sering mengeluh seperti merasa tuli karena mengalami efek samping akibat minum OAT (obat anti
TB) , maupun keluhan yang lainnya, sehingga terkadang enggan minum obat dengan teratur. Berdasarkan hasil wawancara dengan 8 orang penderita TB yang sedang berobat, 3 orang $(37,5 \%)$ mengeluh sering merasa tuli, 4 orang (50\%) mengeluh sering merasa mual dan 1 orang $(12,5 \%)$ tidak memiliki keluhan. Tentu saja hal tersebut dapat juga memicu proses penyembuhan TB yang akan menyebabkan kuman mycobacterium TBC menjadi resisten sehingga terjadi tuberculosis multi drugs resisten (TB MDR).

Solusi yang dapat dilakukan untuk mengatasi permasalahan di atas adalah :

1. Memberikan pelatihan tentang manajemen pengelolaan TB kepada anggota keluarga TB berjumlah 20 orang dengan materi ( penyakit TB, tata aturan minum obat $\mathrm{TB}$, efek samping obat anti TB, tehnik komunikasi efektif untuk memberikan sugesti dan motivasi penderita TB yang menjalani pengobatan penyakit TB untuk konsisten minum obat TB hingga sembuh.

2. Melakukan monitoring minum obat anti TB dalam kurun waktu 1 bulan untuk mengetahui perkembangan pengobatan TB apakah penderita TB tetap meminum obat anti TB meskipun memiliki beberapa keluhan efek samping obat anti TB.

\section{METODE PENGABDIAN}

1. Pelatihan manajemen pengelolaan menggunakan metode ceramah dan diskusi tentang materi dan diskusi.

a. Metode Ceramah.

Metode ini digunakan secara fleksibel agar peserta PKM mampu memahami tentang penyakit TB, efek samping obat anti TB dan bagaimana berkomunikasi untuk mensupport penderita TB minum obat sampai sembuh.. Materi yang diberikan pada kegiatan ini adalah informasi dasar tentang TB, TB MDR, efek samping obat anti TB 
dan penatalaksanaan keluhan akibat efek samping obat anti TB. Materi yang kedua adalah tips komunikasi efektif antara keluarga dan penderita TB untuk mensukseskan bebas TB.

b. Metode Diskusi dan Tanya jawab

Metode ini dilakukan untuk meningkatkan pemahaman dan mengevaluasi materi yang telah di sampaikan pada peserta pelatihan serta dapat mengevaluasi terhadap keberhasilan dari materi yang di sampaikan. Peserta juga diberikan kesempatan untuk bercerita tentang pengalaman pribadi yang berkaitan dengan pengobatan TB kepada peserta yang lain .

2. Monitoring minum obat anti TB

Untuk kegiatan ini, tim PKM menggunakan alat bantu kartu monitoring minum obat anti TB yang akan difollow up melalui telpon/WA maupun secara langsung pada saat penderita TB control dan mengambil obat ke puskesmas Sidomulyo.

\section{HASIL DAN PEMBAHASAN}

Kegiatan pengabdian Masyarakat ini di awali dengan tahap persiapan. Tim pengabdian masyarakat melakukan persiapan alat dan bahan yang di perlukan untuk kegiatan PKM dan selanjutnya melakukan koordinasi dengan Pimpinan Puskesmas Sidomulyo RJ dan Penanggung jawab TB Puskesmas Sidomulyo RJ. Setelah mengadakan koordinasi lanjutan dengan Penanggung jawab TB Puskesmas Sidomulyo RJ, tim pengabdian masyarakat melakukan rapat pembagian tugas pada masing-masing tim pengabdian masyakat diantaranya persiapan ruangan, perlengkapan kegiatan , media sosialisasi LCD, dan dokumentasi kegiatan.

Sasaran dalam kegiatan pengabdian masyarakat ini adalah keluarga dan penderita TB yang berobat di Puskesmas Sidomulyo RJ. Kegiatan dilaksanakan di Aula PKM Sidomulyo RJ.
Sasaran dalam kegiatan pengabdian masyarakat ini adalah keluarga dan penderita TB yang berobat di Puskesmas Sidomulyo RJ. Kegiatan dilaksanakan di Aula PKM Sidomulyo RJ. Hasil kegiatan PKM yang telah dilaksanakan adalah sebagai brikut :

1. Kegiatan pelatihan pemberdayaan keluarga tuberculosis.

Kegiatan ini dilakukan dengan cara tatap muka secara langsung dengan peserta berjumlah 17 orang. Kegiatan PKM dilakukan dengan metode caramah, diskusi dan Tanya jawab . Secara keseluruhan kegiatan PKM yang dilakukan berjalan dengan lancar dan tidak terdapat hambatan.

2. Monitoring minum obat anti TB

Pada kegiatan ini, tim PKM menggunakan alat bantu kartu monitoring minum obat anti TB yang akan difollow up secara langsung pada saat penderita TB control dan mengambil obat ke puskesmas Sidomulyo. Hingga minggu kedua pasca kegiatan PKM ini berdasarkan hasil monitoring kartu minum obat anti TB, $100 \%$ peserta PKM minum obat secara rutin dan dilakukan pada malam hari sebelum tidur untuk menghindari lupa dan menghindari terjadinya keluhan nyeri ulu hati.

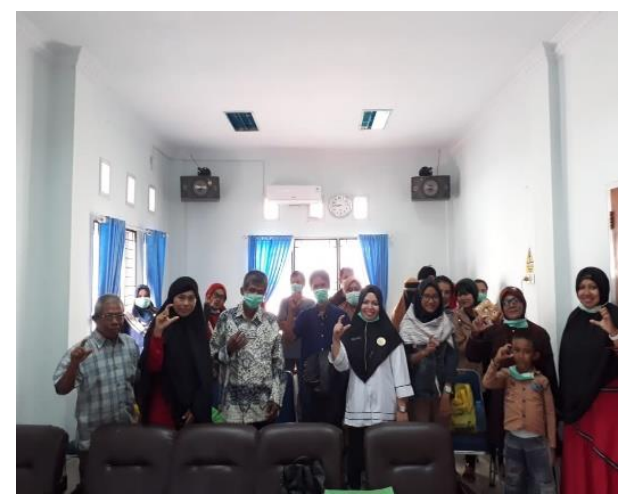




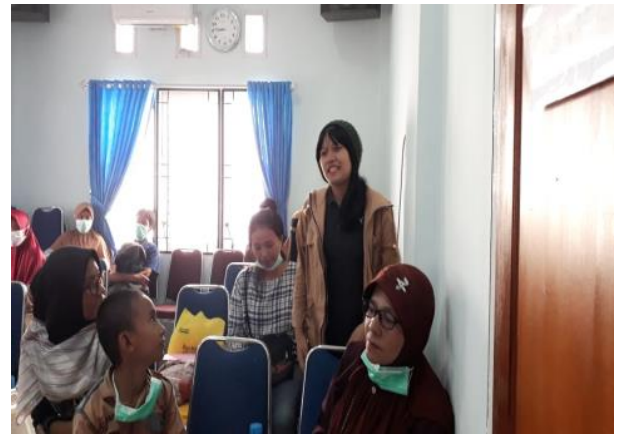

Gambar 1. Foto bersama setelah kegiatan PKM \& salah satu peserta PKM yang bertanya

Hasil kegiatan Pengabdian masyarakat secara garis besar mencakup beberapa komponen sebagai berikut :

a. Keberhasilan target jumlah peserta pelatihan.

Target peserta yang ditetapkan dalam kegiatan tanggal 11

September 2019 berjumlah 20 orang, namun yang hadir saat kegatan berjumlah 17 orang.

b. Tercapainya tujuan kegiatan pelatihan.

Tujuan dari kegiatan PKM ini adalah meningkatnya pemahaman dan wawasan penderita TB dan keluarga tentang pentingnya minum obat hingga sembuh, efek samping obat anti TB dan penatalaksanaannya serta tips komunikasi efektif antara keluarga dan penderita TB untuk mensukseskan bebas TB dengan minum obat hingga sembuh total. Berdasarkan hasil kuesioner 85 $\%$ peserta memiliki pengetahuan dalam kategori baik, $15 \%$ peserta memiliki pengetahuan dalam kategori cukup.

c. Keberhasilan monitoring minum obat anti TB

Tingkat keberhasilan monitoring minum obat anti TB menunjukkan bahwa $100 \%$ peserta PKM yang diberikan kartu control minum obat anti TB minum obat anti $\mathrm{TB}$ secara teratur.

\section{SIMPULAN}

Berdasarkan hasil kegiatan yang telah dilaksanakan dapat disimpulkan pengetahuan peserta PKM tentang penyakit TB dan tehnik berkomunikasi efektif untuk mensupport penderita TB minum obat hingga sembuh mayoritas dalam kategori baik.

Selain itu $100 \%$ penderita TB minum obat secara teratur. Terdapat kontribusi dan respon yang sangat baik dari Pimpinan Puskesmas Sidomulyo RJ dalam upaya mencegah TB MDR. Tim PKM dengan penanggung jawab TB akan membentuk Komunitas peduli TB yang dapat digunakan sebagai media berkonsultasi, saling memotivasi dan dapat mencari solusi apabila terdapat permasalahan selama menjalani pengobatan TB.

\section{UCAPAN TERIMAKASIH}

Ucapan terimakasih tak lupa kami sampaikan kepada semua pihak terutama LPPM UMRI yang telah memberikan bantuan dana sehigga terselenggara kegiatan pengabdian kepada masyarakat ini.

\section{DAFTAR PUSTAKA}

[1]. Aisyiyah, P. T. Panduan ringkas pelaksanaan kegiatan NFM-Global Fund. (2017).

[2]. Kemenkes RI. Tuberkulosis ( TB ). Infodatin Tuberkulosis (2018).

[3]. Alfiah, S. Data kasus TB di kota Pekanbaru siti alfiah. (2018).

[4]. Pernadi, M. O., Rohani, S. \& Simbolon, L. Persepsi Penderita Terhadap Pengobatan Dan Kesembuhan Penyakit Tuberkulosis Paru Di Kota Pekanbaru. Jom Fk 2, 1-14 (2015). 